\title{
The social and cultural impact of tourism development on world heritage sites: a case of the Old Town of Lijiang, China, 2000-2004
}

\author{
T. Yamamura ${ }^{1}$, T. X. Zhang $^{2}$ \& Y. Fujiki ${ }^{1}$ \\ ${ }^{I}$ Department of Tourism Design, Kyoto Saga University of Arts, Japan \\ ${ }^{2}$ Department of Urban and Regional Planning, \\ College of Environmental Sciences, \\ Peking University, People's Republic of China
}

\begin{abstract}
The objective of this paper is to clarify the spatial and social impact on a city caused by its being registered as a World Heritage Site and its transformation into a tourist destination. As part of an investigation of the problems related to rapid development of tourism and its pressures on World Heritage Sites, this study attempted to clarify the issues facing the tourist industry at the Old Town of Lijiang, Yunnan Province, China, a World Heritage Site, by focusing on the tourist shops there and comparing these data as of 2004 with previous data as of 2000. The ways in which both the existing indigenous society (a minority known as the Naxis) and the majority peoples, temporary residents, engage in commercial tourism-related activities were examined. As a result, it was found that, in recent years, the usage of historic buildings has drastically changed. At present, over $90 \%$ of shops are tourist-oriented souvenir shops and restaurants. Furthermore, over $50 \%$ of shopkeepers are temporary residents, mainly Han Chinese, with a large majority renting rooms from indigenous owners. These findings suggest that the location of the residences of the indigenous minority and its culture are rapidly changing as tourism develops.

Keywords: indigenous society, World Heritage Site, Lijiang, China, social impact of tourism, migration of population.
\end{abstract}




\section{Introduction}

\subsection{Background and objectives of research}

The objective of this paper is to clarify the spatial and social impact on a city caused by its being registered as a World Heritage Site and its transformation into a tourist destination. As part of an investigation of the problems related to rapid development of tourism and its pressures on World Heritage Sites, this study attempted to clarify the issues facing the tourist industry at the Old Town of Lijiang, Yunnan Province, China, a World Heritage Site, by focusing on the tourist shops there and comparing these data as of 2004 with previous data as of 2000 .

According to records kept by World Heritage Sites, many World Heritage Site cities have experienced sharp increases in the number of tourists in recent years, and it has been pointed out that these regions may not be able to cope adequately with the social and cultural impact of such increases [1]. On the other hand, there are almost no basic databases of the spatial and social elements that constitute World Heritage Site cities. Although research in this field has been performed by several investigators, Yamamura [1] and Drdácky' [2] have done pioneering studies that have produced tangible social data through on-site studies of the relationship between the urban transition and the tourist industry. Consequently, there is a lack of specific policy measures and management of tourism with respect to most World Heritage Site cities and a lack of ability to cope with these phenomena. Although World Heritage Site cities in China in particular have experienced rapid surges in prosperity in recent years thanks to the tourist industry, almost no data have been accumulated or research studies performed on what has taken place as a consequence of these activities. As a result, it is extremely difficult to assess the value of the heritage and legacies within the rapidly changing public spaces and communities that deserve to be preserved in good condition and passed on to future generations.

In view of the above background considerations, the authors of the present study, who are members of a joint research team from Kyoto Saga University of Arts (Japan), Peking (Beijing) University (China), and Wakayama University (Japan) believe there is an urgent need to compile a database of the spatial and social elements constituting World Heritage Site cities and to identify the spatial and social impact caused by listing as a World Heritage Site and the transition into a tourist destination.

\subsection{Related studies and characteristics of the present research}

There appear to be no cases of comprehensive databases concerning the spatial and social elements that constitute a World Heritage Site city, even if one searches worldwide for examples with a narrow focus. With respect to useful materials about the Old Town of Lijiang, there is a 1997 study by Jiang summarizing the spatial structure of streets and waterways [3] and a series of 
studies by Yamamura $[1,4]$ concerning the transformation of residential structures.

This study shares a common awareness of the issues with such research; moreover, it is a very useful in terms of materials and originality with respect to the following three points: (1) it is focused on the importance of adequately protecting the totality of a World Heritage Site city, including the surrounding local social and cultural environment as well as buildings and other elements of the physical environment; (2) it is an initial attempt to compile the social elements of Lijiang into a comprehensive database; and (3) it attempts to make a multifaceted analysis of the impact resulting from its listing as a World Heritage Site and its transformation into a tourist destination, based on primary materials from field work.

\subsection{Outline of Lijiang}

Lijiang Municipality is located in the northwest corner of Yunnan province in south-west China (Fig. 1). The old town of Lijiang is the historical centre of the city and the great majority of the population are Naxi, an indigenous ethnic minority group, they retain their own language, pictographs and religion [5].

The old town of Lijiang was listed by UNESCO as a World Heritage Site in December 1997 in appreciation of the architecture of its dwellings and the historical townscape as a collective entity. The old town of Lijiang has a population of 13,780 housed in some 4,564 wooden dwellings crowded into an area of 350.2 ha [6]. The whole area of the old town was designated as a conservation area by the government of Yunnan Province in 1997.

Yamamura [1] has already reported that it would seem reasonable to regard 1995 or thereabouts as the turning point, that is, the time when the increase in the number of visitors to Lijiang and the emergence of the business category of tourism began.

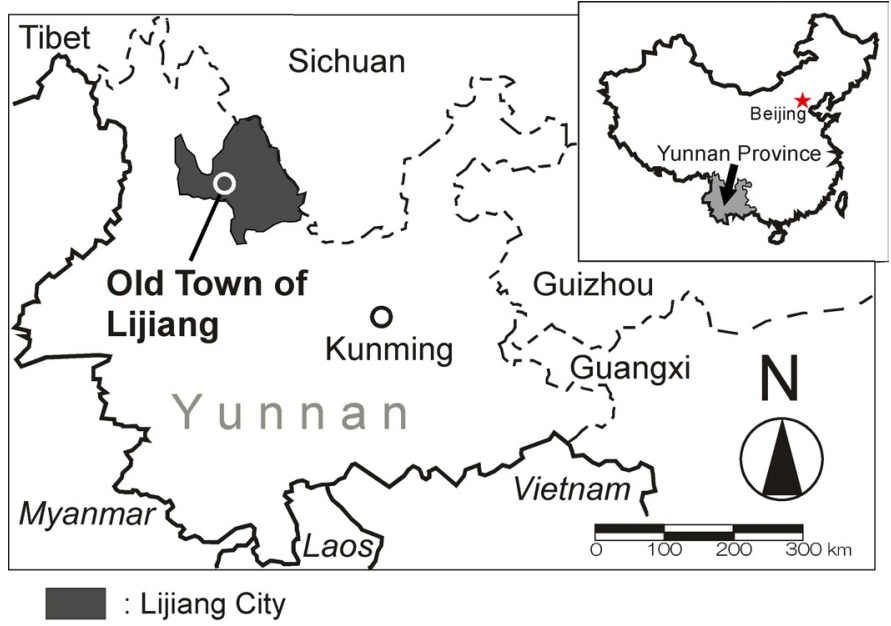

Figure 1: Location of Lijiang (source: map courtesy of the authors). 


\subsection{Research methods}

This study, which covers the core of the Old Town of Lijiang (measuring approximately 200 meters east-west and 230 meters north-south, fig. 2), discusses the results of a June 2000 study by Yamamura [1], which covered all of the commercial buildings that exist in this district, as well as the results of an August 2004 (9-25 August) study of the same district by the authors.

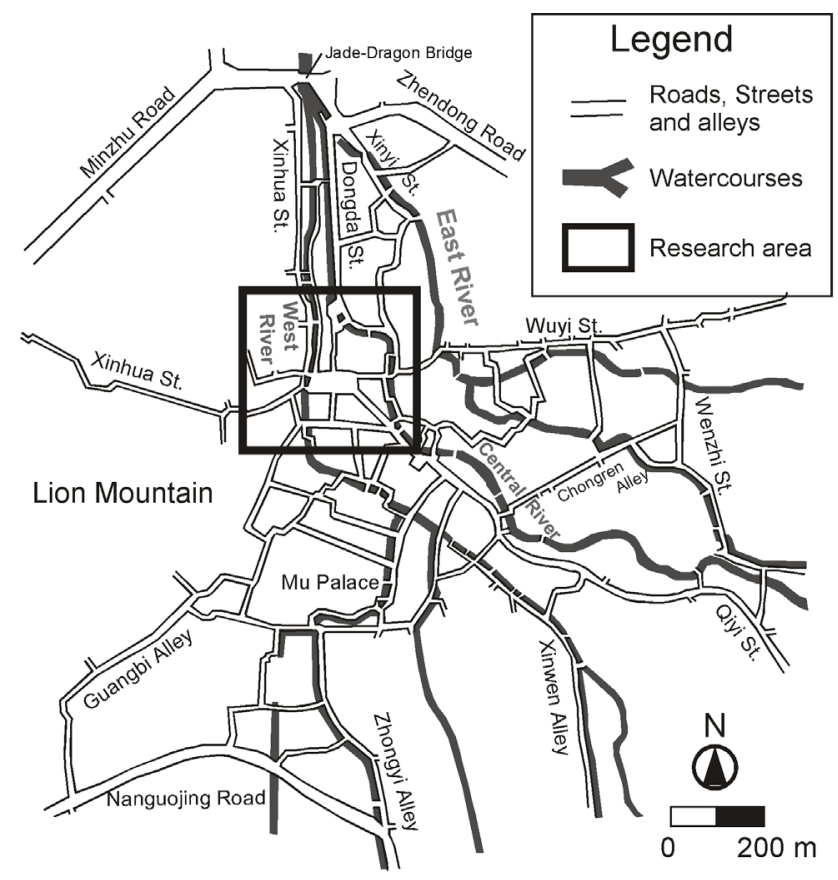

Figure 2: Research area (source: map courtesy of Yamamura [1]).

An on-site survey for both periods was used to classify retail and service businesses and categories of shop operators. Because in China, business directories and community plans are not open to the public, on-site inspection was conducted to identify the items on sale and the services provided. Furthermore, to make up for the lack of municipal information such as business directories, a person-to-person interview on business conditions was conducted with each shop operator covered by the survey (operators themselves in self-run outlets; relevant information-desk staff in corporate outlets).

For purposes of this study, a single shop unit was defined as a section of a building in some manner demarcated from adjacent shops and being used by a single independent operator. This definition was adopted because premises were frequently encountered that were originally single units and were now partitioned into segments and conversely, that were originally multiple units but were now one unit after the removal of dividing walls. 


\section{Results}

\subsection{The actual transformation of building applications in the Old Town of Lijiang}

Tables 1 and 2 summarize the business status and number of units that were verified for all commercial buildings in the center of the Old Town of Lijiang as of 2000 and 2004, respectively. Businesses were classified into two categories: 'tourist shops' and 'general shops'.

Table 1: $\quad$ List of business types (as of June 2000).

\begin{tabular}{|c|c|c|}
\hline Business categories & Number of shops & Percentage \\
\hline Tourist shops & 189 & $66.1 \%$ \\
\hline Commodity sales/Service industry ${ }^{\prime \prime}$ & 145 & $50.7 \%$ \\
\hline Providers of food and drink ${ }^{2}$ & 38 & $13.3 \%$ \\
\hline Accommodations ${ }^{3,}$ & 6 & $2.1 \%$ \\
\hline General shops & 97 & $33.9 \%$ \\
\hline Commodity sales/Service industry ${ }^{4}$ & 88 & $30.8 \%$ \\
\hline Providers of food and drink ${ }^{3}$ & 9 & $3.1 \%$ \\
\hline Overall & 286 & $100.0 \%$ \\
\hline
\end{tabular}

Note 1: E.g., souvenir shop, etc.

Note 2: E.g., restaurant, coffee shop, bar, etc.

Note 3: There are two types of accommodations; company-owned guest facilities and private homes providing meals and lodging to travellers. With respect to accommodation facilities, all accommodation rooms were lumped together and counted as one housing unit.

Note 4: E.g., general store, clothing store, beauty parlour, etc.

Note 5: E.g., local eating house.

Table 2: $\quad$ List of business types (as of August 2004).

\begin{tabular}{|l|r|r|}
\hline Business categories & Number of shops & Percentage \\
\hline Tourist shops & $\mathbf{3 1 2}$ & $\mathbf{9 2 . 3 \%}$ \\
\hline Commodity sales/Service industry & 258 & $\mathbf{7 6 . 3 \%}$ \\
\hline Providers of food and drink & 39 & $11.5 \%$ \\
\hline Accommodations & & 15 \\
\hline General shops & 15 & $4.4 \%$ \\
\hline Commodity sales/Service industry & $\mathbf{2 6}$ & $\mathbf{7 . 7 \%}$ \\
\hline Providers of food and drink & 20 & $5.9 \%$ \\
\hline Overall & 6 & $1.8 \%$ \\
\hline
\end{tabular}

Note 1: As of August 2004, there were no company-owned guest facilities; all were private homes providing meals and lodging to travellers.

Note 2: As of August 2004, there were no beauty parlours. This is a result of the local government's transition policy.

- Tourist shops: these targeted tourists as users of their services and purchasers of their goods. When multiple business activities are concurrently carried out, businesses catering for tourists as their main commercial activity are classified as tourist shops. 
- General shops: these targeted general residents as users of their services and purchasers of their goods. Alternatively, shops catering to an unspecified variety of customers, which could include tourists, such as outlets for foodstuff and general goods, hairdressers and other services, also belong in this category. Further, according to the particulars of business content, businesses were sub-classified into categories of commodity sales/service industry, providers of food and drink, and establishments offering overnight accommodation.

As a result, it was found that the commercialization of the old town centre had progressed from 2000 through 2004, with the total number of stores increasing by about 50 units. It was found that the commercialization of this area was largely attributable to the flourishing tourist industry centred on souvenirs. This was indicated by the 1.5-fold increase in the number of building units in the tourist industry category, especially the notable growth of tourist-oriented sales (souvenir shops).

\subsection{The actual social transformation in the Old Town of Lijiang}

Tables 3 and 4 show whether the shop operators surveyed are individual or corporate entities and classify shops according to business category. In addition, the table gives the racial composition of all of the individual operators, referring to their family registry classification under Chinese law [1]. Those with permanent residential qualification for Lijiang are classified as permanent inhabitants and those with temporary permits as temporary residents.

Table 3: $\quad$ Categories of shop operators (as of June 2000).

\begin{tabular}{|c|c|c|c|c|c|c|c|c|c|}
\hline \multirow{4}{*}{$\begin{array}{c}\text { Business } \\
\text { categories }\end{array}$} & \multicolumn{8}{|c|}{ Categories of shop operators } & \multirow{4}{*}{ Overall } \\
\hline & \multicolumn{6}{|c|}{ Individual operators } & \multirow{3}{*}{\begin{tabular}{|c} 
Corpo- \\
rate \\
entities
\end{tabular}} & \multirow{3}{*}{$\begin{array}{c}\text { Uniden- } \\
\text { tified }\end{array}$} & \\
\hline & \multicolumn{3}{|c|}{ Permanent inhabitants } & \multicolumn{3}{|c|}{ Temporary residents } & & & \\
\hline & $\begin{array}{c}\text { The } \\
\text { Naxis }\end{array}$ & $\begin{array}{l}\text { The } \\
\text { Hans }\end{array}$ & Others & $\begin{array}{l}\text { The } \\
\text { Hans }\end{array}$ & $\begin{array}{c}\text { The } \\
\text { Naxis }\end{array}$ & Others & & & \\
\hline Tourist shops & \multirow[b]{2}{*}{48} & \multirow[b]{2}{*}{6} & \multirow[b]{2}{*}{1} & \multirow[b]{2}{*}{70} & \multirow[b]{2}{*}{1} & \multirow[b]{2}{*}{15} & \multirow[b]{2}{*}{4} & \multirow[b]{2}{*}{0} & \multirow[b]{2}{*}{145} \\
\hline $\begin{array}{l}\text { Commodity sales/ } \\
\text { Service industry }\end{array}$ & & & & & & & & & \\
\hline $\begin{array}{l}\text { Providers of food } \\
\text { and drink }\end{array}$ & 26 & 2 & 0 & 7 & 0 & 3 & 0 & 0 & 38 \\
\hline Accommodations & 5 & 0 & 0 & 0 & 0 & 0 & 1 & 0 & 6 \\
\hline \multirow{2}{*}{ Sub-total } & 79 & 8 & 1 & 77 & 1 & 18 & 5 & $\mathbf{0}$ & 189 \\
\hline & $41.8 \%$ & $4.2 \%$ & $0.5 \%$ & $40.7 \%$ & $0.5 \%$ & $9.5 \%$ & $2.6 \%$ & $0.0 \%$ & $100.0 \%$ \\
\hline General shops & \multirow[b]{2}{*}{42} & \multirow[b]{2}{*}{5} & \multirow[b]{2}{*}{2} & \multirow[b]{2}{*}{17} & \multirow[b]{2}{*}{0} & \multirow[b]{2}{*}{4} & \multirow[b]{2}{*}{15} & \multirow[b]{2}{*}{3} & \multirow[b]{2}{*}{88} \\
\hline $\begin{array}{l}\text { Commodity sales/ } \\
\text { Service industry }\end{array}$ & & & & & & & & & \\
\hline $\begin{array}{l}\text { Providers of food } \\
\text { and drink }\end{array}$ & 2 & 0 & 0 & 7 & 0 & 0 & 0 & 0 & 9 \\
\hline \multirow{2}{*}{ Sub-total } & 44 & 5 & 2 & 24 & 0 & 4 & 15 & 3 & 97 \\
\hline & $45.4 \%$ & $5.2 \%$ & $2.1 \%$ & $24.7 \%$ & $0.0 \%$ & $4.1 \%$ & $15.5 \%$ & $3.1 \%$ & $100.0 \%$ \\
\hline \multirow{2}{*}{ Overall } & 123 & 13 & 3 & 101 & 1 & 22 & 20 & 3 & 286 \\
\hline & $43.0 \%$ & $4.5 \%$ & $1.0 \%$ & $35.3 \%$ & $0.3 \%$ & $7.7 \%$ & $7.0 \%$ & $1.0 \%$ & $100.0 \%$ \\
\hline
\end{tabular}


Table 4: $\quad$ Categories of shop operators (as of August 2004).

\begin{tabular}{|c|c|c|c|c|c|c|c|c|c|}
\hline \multirow{4}{*}{$\begin{array}{c}\text { Business } \\
\text { categories }\end{array}$} & \multicolumn{8}{|c|}{ Categories of shop operators } & \multirow{4}{*}{ Overall } \\
\hline & \multicolumn{6}{|c|}{ Individual operators } & \multirow{3}{*}{\begin{tabular}{|c} 
Corpo- \\
rate \\
entities
\end{tabular}} & \multirow{3}{*}{$\begin{array}{c}\text { Uniden- } \\
\text { tified }\end{array}$} & \\
\hline & \multicolumn{3}{|c|}{ Permanent inhabitants } & \multicolumn{3}{|c|}{ Temporary residents } & & & \\
\hline & $\begin{array}{l}\text { The } \\
\text { Naxis }\end{array}$ & $\begin{array}{l}\text { The } \\
\text { Hans }\end{array}$ & Others & $\begin{array}{l}\text { The } \\
\text { Hans }\end{array}$ & $\begin{array}{c}\text { The } \\
\text { Naxis }\end{array}$ & Others & & & \\
\hline Tourist shops & & & & & & & & & \\
\hline $\begin{array}{l}\text { Commodity sales/ } \\
\text { Service industry }\end{array}$ & 71 & 0 & 3 & 104 & 0 & 58 & 1 & 19 & 256 \\
\hline $\begin{array}{l}\text { Providers of food } \\
\text { and drink }\end{array}$ & 15 & 0 & 1 & 15 & 1 & 3 & 0 & 4 & 39 \\
\hline Accommodations & 5 & 0 & 0 & 8 & 0 & 2 & 0 & 0 & 15 \\
\hline Subtot & 91 & 0 & 4 & 127 & 1 & 63 & 1 & 23 & 310 \\
\hline Sub-total & $29.4 \%$ & $0.0 \%$ & $1.3 \%$ & $41.0 \%$ & $0.3 \%$ & $20.3 \%$ & $0.3 \%$ & $7.4 \%$ & $100.0 \%$ \\
\hline General shops & & & & & & & & & \\
\hline $\begin{array}{l}\text { Commodity sales/ } \\
\text { Service industry }\end{array}$ & 12 & 1 & $\mathbf{0}$ & 1 & $\mathbf{0}$ & 2 & 3 & 1 & 20 \\
\hline $\begin{array}{l}\text { Providers of food } \\
\text { and drink }\end{array}$ & 4 & 0 & 0 & 2 & 0 & 0 & 0 & 0 & 6 \\
\hline$S_{1}$ & 16 & 1 & 0 & 3 & $\mathbf{0}$ & 2 & 3 & 1 & 26 \\
\hline Sub-total & $61.5 \%$ & $3.8 \%$ & $0.0 \%$ & $11.5 \%$ & $0.0 \%$ & $7.7 \%$ & $11.5 \%$ & $3.8 \%$ & $100.0 \%$ \\
\hline & 107 & 1 & 4 & 130 & 1 & 65 & 4 & 24 & 336 \\
\hline $\mathbf{U}$ & $31.8 \%$ & $0.3 \%$ & $1.2 \%$ & $38.7 \%$ & $0.3 \%$ & $19.3 \%$ & $1.2 \%$ & $7.1 \%$ & $100.0 \%$ \\
\hline
\end{tabular}

Note 1: The total number of shop operators differs from the total number of shops in Table 2, because in some cases, one operator runs more than one shop.

As of August 2004, 90\% of all shops (308 units) were sole proprietorships. Of these, 112 units (about $33 \%$ of the total) were managed by the permanent population, consisting mainly of the Naxi ethnic group, which are the indigenous inhabitants of Lijiang. However, 196 units (about $58 \%$ of the total) were operated by members of the inflowing population, mainly Han Chinese, the major ethnic group of China. As of 2000, the permanent population slightly outnumbered the inflowing population. However, as of 2004, the inflowing population had grown to nearly double the size of the permanent population. The proportion of the inflowing population consisting of managers of tourist industry businesses showed particularly notable growth. Consequently, it was found that the growth of tourist-related businesses here is closely related to the inflow of the external population.

\section{Discussion}

Restrictions on population movement have been relaxed since the second half of the 1980s. Family registers are controlled by the Bureau of Public Security, and anyone wishing to reside in Lijiang must undergo screening and complete official documentation procedures at a local office controlled by the Bureau of Public Security before being issued a temporary permit, valid for a specified period of no longer than 1 year. Upon the expiration of this permit, an extension of up to 1 year is normally possible after a second official examination. The 
stringent legal restrictions on changing a registered permanent residential qualification make it extremely difficult for temporary residents to acquire permanent residential qualification in Lijiang. (Information gained from interviews conducted with Lijiang county Bureau of Public Security in June 2000 and Dayan Town Government in November 2000.)

As noted above, Chinese people now enjoy a degree of freedom of movement, while the country is also seeing the development of a real-estate market. In such circumstances and according to market principles, there will naturally come to reside in the locality people capable of putting the land and buildings to effective use. As to the tourism business, it is easy to imagine that this will mean the influx of people that possess sufficient capital to open shops and sufficient know-how to raise profits. Further, as Yamamura reports [1, 6], given the lack of government policy for providing the local community with aid to develop industry, temporary residents are likely to have an advantage in store management over existing inhabitants, in that the temporary residents have more financial capital and experience. Such a situation will result in an increasingly greater proportion of temporary residents coming to operate tourism-related shops, while many former inhabitants will consider it more to their advantage to move out of the old town and live off rents accrued from leasing their former rooms to temporary residents.

Temporary residents are applying business specialization and aggressively developing the tourism industry along commercial principles, while the Naxi, who are the successors to the original local culture, have proved incapable of bringing to bear sufficient independent initiative in the creation of the tourism industry. The result has been that the content of much of the tourism industry has little contextual bearing on the locality. This gives rise to the problem that tourism-related products do not successfully serve in communicating the allure of the locality, thus adversely affecting the process of host-guest exchange.

Since 1985 , to reduce the extremely high population density and improve housing conditions in the old town, the Lijiang Autonomous County Government has been constructing a new town, which lies adjacent to the old town. According to the local government report [6], initially, thanks to that policy, the population density had been reduced appropriately. However, because the World Heritage registration in 1997 caused drastic tourism development, leasing of rooms to temporary residents by the indigenous Naxi people accelerated. In consequence, many indigenous residents moved from the old town to the new town.

The Lijiang Municipality Government described the situation as "anomalous emigration" and "serious crisis of the local culture" [6]. To that end, the city government began implementing a new policy called "benefiting the people (indigenous inhabitants-first) policy" in January 2004 in order to help increase the ratio of the indigenous population of the old town. This policy provides 10 Yuen subsidies (approximately 1.25 US\$) per person each month to indigenous inhabitants who have lived or used to live in the old town before the World Heritage registration in 1997. If people who are living outside of the old town but formerly lived in the old town return to live in the old town, they possess the 
right to receive subsidies from the local government (from interview survey conducted with a local government official at Administration Commission on Conservation and Management of the Old Town of Lijiang, March 2005).

However, if they lease their rooms in the old town, they can get hundreds to thousands Yuan per room each month. Therefore, it is very difficult to evaluate the effectiveness of the 10-Yuan subsidy each month compared with income that can be gained from leasing their rooms.

\section{Conclusions and implications}

A rapid growth of tourist industry businesses reflected in building applications and related phenomena of social transformation are taking place as described above in the Old Town of Lijiang. They imply that a re-evaluation of tourism and conservation policy is essential for the protection of the totality of a historic town as a heritage site.

In the light of these findings, one can point to the following challenges that remain with regard to the existing tourism industry and its management in this locality. It will first be essential to include planning formulated in accordance with market principles in any policy for the preservation of the old town. It is necessary to foster the kind of local industry that will enable the local community to keep abreast of the high economic value and high rental charges of the protected buildings. If this is to be achieved, it will be necessary to take squarely into account the fact that, despite the opportunities of the local community to commercialize its own distinctive culture, the lack of specific forms of support has failed to create an internally generated industry [1]. Once such policies have stimulated organizations and networks, and thereby invigorated attempts to create industry based on the local context, tourismrelated activities can come to play a part in conveying local appeal to visitors and enabling the original culture of the heritage site to be perpetuated. A further important issue to address is how temporary residents can best use their capital and know-how to engage in tourism-related activities as hosts best qualified to convey local appeal.

Up till recently, the local government had no policy to cope pro-actively with such issues. However, a leadership and framework for the protection and management of the old town has been rapidly put into place since the 2002 change in jurisdiction from Lijiang Prefecture to Lijiang Municipality. More specifically, the Lijiang Municipality government has already begun to undertake the following countermeasures: (1) Addressing the abrupt and needless transformation into a tourist destination: placing limitations on the number of stores and business structure by controlling the number of issuances of the "zhun ying zheng" (permit to operate a business); (2) Addressing the sudden transformation of the society: Carrying out a policy of "benefiting the people" by providing subsidies to those residents before Lijiang's listing as a World Heritage Site, with the objective of raising the ratio of indigenous people in the old town district. In addition, (3) the municipal government is currently 
moving ahead to put into place a control system covering the historical townscape and building design.

Hereafter, it is believed that some of the effects of these policies can be evaluated by investigating the transformation of categories of business and shop operators using methodology presented in this paper. Such a perspective, moreover, could be applied not only to World Heritage city sites, but also extensively with respect to other historical cities and cities attempting to promote tourism.

\section{References}

[1] Yamamura, T., Indigenous society and immigrants: tourism and retailing in Lijiang, China, a World Heritage city. TOURISM: An International Interdisciplinary Journal, Vol. 51/No.2, pp. 215-235, 2003.

[2] Drdácky', M.F., Impact and Risks of Tourism in Cultural Heritage Environment. Proc. of the Scientific Conference: Preservation, Development and Monitoring of Historic Cities in 21st Century, ICOMOS: Athens, 2002.

[3] Jiang, G., (ed.). Lijiang: the Beautiful Naxi Homeland, China Architecture \& Building Press: Beijing, 1997.

[4] Yamamura, T., Dongba Art in Lijiang, China: Indigenous Culture, Local Community and Tourism (Chapter 13). Indigenous Tourism: The Commodification and Management of Culture, eds. C. Ryan \& M. Aicken, Elsevier Science Ltd.: Oxford, pp.181-199, 2005.

[5] Guo, J., Duan, Y. \& Yang, F., Introduction to Minority Tribes in Yunnan, Yunnan People's Publishing House: Kunming, 1999.

[6] Office of Foreign Affairs \& Overseas Chinese Affairs, People's Government of Lijiang Municipality (ed.). Proc. of UNESCO Conference/Workshop Cultural Heritage Management And Tourism: Models for Cooperation among Stakeholders, Yunnan Nationalities Publishing House: Kunming, 2003. 